\title{
ANALISA PERSEPSI MAHASISWA TERHADAP PELAKSANAAN AUDIT PADA OPINI WTP DALAM KAITANNYA DENGAN TANGGUNG JAWAB DAN INDEPENDENSI AUDITOR
}

\author{
Siska Cantika Pakambi ${ }^{1}$, Inggriani Elim ${ }^{2}$, Sintje Rondonuwu ${ }^{3}$ \\ ${ }^{1,2,3}$ Fakultas Ekonomi dan Bisnis, Jurusan Akuntansi, Universitas Sam Ratulangi, Jl.Kampus Bahu, \\ Manado, 95115, Indonesia \\ E-mail : Pakambi8@gmail.com
}

\begin{abstract}
Expectation gap in auditing is the term used to signify the difference in expectation of wha auditor belived about auditor's responsibility and what financial statement users belived about auditor's actual responsibility. This study was aimed at finding out the difference of perception between the students of accounting and students of management on audit implementation on unqualified opinion in relation to responsibility and independence of auditor. This was a study using quantitative method. The population consisted of the eighth semester students of accounting and students of management Departement of S1 Program. The method of sampling used was purposive sampling method. The number of questionnaires distributed was 60 and all of them could be used in this study. The method of analysis for hypothesis testing was Independent Sample T-Test. The tool of data analysis used was SPSS version 23.0 program. Based on the result of Independent Sample T-Test analysis it was found that (1) There is a difference of perception among the students of accounting and students of management on auditor's responsibility.(2) There is a difference of perception among the students of accounting and students of management on auditor's independence.

Keywords: Implementation on Unqualified Opinion, Expectation Gap, Students, Auditor's Responsibility and Auditor's independence.
\end{abstract}

\section{PENDAHULUAN}

Perkembangan profesi akuntan publik itu cukup pesat, sesuai dengan perkembangan perusahaan dan tuntutan masyarakat atas jasa yang bisa diberikan oleh akuntan publik. Salah satunya adalah jasa audit. Manajemen sebagai pengelola perusahaan, dalam mempertanggungjawabkan sumber daya dan dana kepada pihak-pihak yang berkepentingan terhadap perusahaan, memerlukan pihak ke tiga yang independen untuk menguji beberapa laporan yang telah dibuat oleh manajemen (yaitu laporan keuangan), (Indrarto, 2005).

Selain itu, kasus yang melibatkan kegagalan auditor independen dalam mendeteksi kecurangan antara lain adalah kasus PT Kimia Farma (2001) dimana manajemen Kimia Farma melaporkan adanya laba bersih sebesar Rp 132 milyar, dan laporan tersebut di audit oleh Hans Tuanakotta \& Mustofa (HTM) sedangkan Kementerian BUMN dan Bapepam menyajikan kembali laporan keuangan tersebut dan mendapatkan keuntungan yang diungkapkan hanya sebesar Rp 99,56 miliar, atau lebih rendah sebesar Rp 32,6 milyar atau dari laba awal yang telah dilaporkan. HTM dinyatakan tidak mampu mendeteksi laporan keuangan tersebut apakah mengandung unsur kecurangan atau tidak (Koroy, 2008).

Opini WTP merupakan opini yang paling baik di bandingkan dengan opini yang lain. Pencapaian opini WTP bukanlah hal yang mudah. Proses menyusun laporan keuangan yang sesuai SAP perlu perjuangan ekstra. Kelemahan pada Sistem Pengendalian Internal (SPI), keterbatasan SDM yang paham akuntansi pemerintahan dan ditambah ruwet dengan berbagai kepentingan politik yang menunggangi sehingga terjadi penggunaan anggaran yang 
cenderung menabrak aturan menyebabkan penyajian laporan keuangan yang akuntabel benarbenar bukan hal yang mudah. Pemberian apresiasi atas pencapaian opini WTP kepada lembaga pemerintah menjadi hal yang wajar dengan adanya berbagai kesulitan tersebut (Auliyana, 2017). Opini wajar adalah hasil pemeriksaan auditor eksternal terhadap entititas atas asersi manajemen atas laporan keuangan dalam suatu periode akuntansi yang disusun berdasarkan Standart Akuntansi yang berterima umum dan diaudit menggunakan norma pemeriksaan akuntan dan Standart Pemeriksaan Keuangan Negara (Pada entitas sektor publik pemerintah) dan Standart Profesional Akuntan Publik (SPAP) pada Entitas diluar keuangan Negara, Rusliyawati dan Halim (2008).

Berbagai upaya dilakukan untuk menjadikan dunia profesi akuntan menjadi lebih baik dan professional. Tetapi pada kenyataannya masih banyak terdapat masalah yang timbul berkaitan dengan dunia profesi akuntan, baik dalam pelaksanaan maupun hasil kerja yang dihasilkan oleh organisasi jasa profesi akuntan. Salah satu masalah yang muncul dan berkembang saat ini dari berbagai permasalahan yang dihadapi profesi akuntan adalah masalah expectation gap dalam proses dan hasil dari pelaksanaan audit. Expectation gap pada dasarnya didefinisikan sebagai perbedaan antara auditor dengan pengguna laporan keuangan mengenai tingkat kinerja yang diharapkan dari pertimbangan hasil yang dilakukan oleh auditor (Shaikh \& Talha, 2003). Perbedaan ini tidak saja terjadi antara pihak auditor dan pengguna jasa audit, tapi juga telah melibatkan masyarakat. Hal ini dikarenakan fungsi dan peran auditor yang cukup penting saat ini berkaitan dengan masalah transparansi dan keterbukaan organisasi baik itu organisasi swasta maupun pemerintah. Berkaitan dengan masalah expectation gap di Indonesia, IAI menyatakan bahwa selama ini jika terjadi kesalahan berkaitan dengan bermasalahnya perusahaan yang telah diaudit dengan hasil laporan audit wajar, maka kesalahan selalu dilimpahkan pada auditor (Gamaliel, 2007), oleh karena itu independensi auditor sangat penting dalam melaksanakan audit, karena sekarang ini auditor bukan hanya bertanggung jawab kepada pemakai laporan keuangan saja namun juga masyarakat.

\section{TINJAUAN PUSTAKA}

\subsection{Kesenjangan Ekspektasi (Expectation Gap)}

Audit expectation gap untuk pertama kali diperkenalkan oleh Liggio (1974) yang mendefinisikan bahwa audit expectation gap merupakan perbedaan pandangan mengenai tingkatan kinerja yang diharapkan antara akuntan independen dengan pengguna laporan keuangan, seperti direktur keuangan, analis keuangan, analis investasi, dan jurnalis investasi. Nasser \& Ayuningtyas (2007) menyebutkan bahwa istilah expectation gap awal mula penggunaannya dari Amerika Serikat, pada tahun 1974, komisi tanggung jawab auditor yang dibentuk oleh American Institute of Ceritified Public Accountants (AICPA) dan dikenal dengan nama Cohen Commission yang bertujuan untuk menanggapi kritik - kritik masyarakat mengenai kualitas kinerja auditor pada saat itu.

Expectation gap di dalam auditing adalah suatu fenomena yang terjadi karena adanya perbedaan persepsi tentang apa yang dipercaya oleh auditor yang menjadi tanggung jawabnya dengan apa yang dipercaya pemakai laporan keuangan mengenai tanggung jawab auditor yang sesungguhnya (Guy \& Sullivan 1988, Gramling \& Wallace 1996). Sedangkan menurut Dixon et al (2006) perbedaan antara apa yang diharapkan oleh pemakai jasa audit dari profesi akuntan dan apa yang sesungguhnya dilakukan oleh profesi akuntan tersebut, itulah yang disebut kesenjangan audit. Yang perlu ditekankan dalam expectation gap adalah harapan masyarakat atau para pemakai laporan keuangan terhadap auditor tentang laporan keuangan secara nyata melebihi peran auditor dan opini auditnya. 


\subsection{Tanggung Jawab Auditor}

Tanggung jawab auditor didasarkan pada etika profesionalnya yang telah disepakati oleh IAI termasuk mematuhi prinsip akuntansi yang berlaku, standar audit dank ode etik akuntan Indonesia. Adapun prisip etika profesi akuntan menurut IAI sebagai berikut :

1. Tanggung jawab profesi

2. Kepentingan Publik

3. Integritas

4. Objektivitas

5. Kompetensi dan Kehati-hatian Profesional

6. Kerahasiaan

7. Perilaku Profesional

8. Standar Teknis

Profesionalisme merupakan sikap bertanggungjawab terhadap apa yang telah ditugaskan kepadanya. Sikap profesionalisme akan mengambil keputusan berdasarkan pertimbangan yang dimilikinya yaitu berdasarkan pengabdian pada profesi, kewajiban social, kemandirian, keyakinan terhadap profesi dan hubungan dengan sesama profesi (Agusti dan Pertiwi, 2013).

Auditor memiliki tanggung jawab untuk mendeteksi berbagai jenis salah saji material, termasuk kesalahan, penyimpangan yang diakibatkan oleh tindakan illegal atau yang melawan hukum. Bukti audit haruslah diperoleh dengan cukup dan tepat untuk memberikan dasar dalam menyatakan pendapat dalam laporan auditor.

The Auditing Practice Committee, yang merupakan cikal bakal dari Auditing Practices Board, ditahun 1980, memberikan ringkasan (summary) tanggung jawab auditor:

1. Perencanaan, Pengendalian dan Pencatatan.

2. Sistem Akuntansi.

3. Bukti Audit.

4. Pengendalian Intern.

5. Meninjau Ulang Laporan Keuangan yang Relevan.

6. Opini Auditor, auditor bertanggung jawab dalam pemberian opini. Berikut opini auditor:

a. Pendapat Wajar Tanpa Pengecualian.

b. Pendapat Wajar Dengan Pengecualian.

c. Pendapat tidak wajar.

d. Penolakan Memberikan Pendapat.

e. Penolakan memberikan pendapat

Persepsi mahasiswa terhadap pelaksanaan audit pada opini WTP dalam kaitannya dengan tanggung jawab auditor adalah merencanakan dan melaksanakan audit untuk mendeteksi kesalahan material pada laporan keungan baik yang disebabkan oleh kekeliruan atau kecurangan serta menyatakan suatu opini atas laporan keuangan tersebut berdasarkan auditnya.

Berdasarkan uraian tersebut maka dirumuskan hipotesis pertama :

H1: Terdapat perbedaan persepsi masalah tanggung jawab auditor atas pelaksanaan audit pada opini WTP pada mahasiswa jurusan akuntansi dan manajemen.

\subsection{Independensi Auditor}

Seperti yang telah dijelaskan sebelumnya auditing adalah proses pengumpulan dan pengevaluasian bahan bukti tentang informasi yang dapat diukur mengenai suatu entitas ekonomi yang dilakukan oleh seseorang yang kompeten dan independen untuk dapat menentukan dan melaporkan kesesuaian informasi yang dimaksud dengan kriteria-kriteria 
yang telah ditetapkan (Arens \& Loebbecke, 2012). Sedangkan yang dimaksud dengan orang yang kompeten dan independen tersebut adalah auditor.

Pada masa-masa awal perkembangan profesi akuntan publik, belum ditemukan definisi yang resmi mengenai independensi. Akan tetapi seiring dengan makin berkembangnya profesi akuntan publik maka dibuat definisi resmi mengenai independensi yang diawali dengan dirumuskannya General Accepted Auditing Standards (GAAS) pada tahun 1947 yang mengharuskan seorang auditor yang tidak bersikap bias dalam menjalankan tugas dari kliennya (Carmichael, 1999). American Institute of Certified public Accountant (AICPA) dalam Mayangsari (2003) menyatakan bahwa independensi adalah suatu kemampuan untuk bertindak berdasarkan integritas dan objektivitas. Integritas berhubungan dengan kejujuran intelektual seorang akuntan yang berupa prinsip moral yang jujur, tegas, memandang dan mengungkapkan fakta seperti apa adanya. Sedangkan yang dimaksud dengan objektivitas adalah sikap mental yang tidak memihak, baik kepada kepentingan pribadi ataupun orang lain, dalam melakukan tugas pemeriksaan.

Arens \& Loebbecke (2012) memberikan pengertian tentang independensi dalam auditing, yakni sikap yang berpegang pada pandangan yang tidak memihak dalam penyelenggaraan tes audit, evaluasi hasil pemeriksaan, dan penyusunan laporan pemeriksaan. Standar Profesional Akuntan Publik (SPAP) menyatakan bahwa independensi yang dimiliki oleh seorang akuntan publik berbeda dengan sikap yang dimiliki oleh seorang penuntut dalam perkara pengadilan yang cenderung memihak pada kepentingan korban. Sikap tidak memihak yang dimiliki oleh akuntan publik lebih dapat disamakan dengan sikap tidak memihaknya seorang hakim yang tidak memihak siapapun. Dalam pekerjaannya, akuntan publik mengakui kewajiban untuk jujur tidak hanya kepada manajemen dan pemilik perusahaan, namun juga kepada kreditur dan pihak lain yang menyerahkan kepercayaan atas laporan keuangan yang independen. Independensi sendiri dapat dibedakan menjadi dua aspek, yaitu independensi dalam kenyataan (independent in fact) dan independensi dalam penampilan (independent in appearance). Independensi dalam kenyataan berkaitan dengan objektivitas akuntan publik untuk bersikap bebas dari pengaruh kepentingan pribadi. Sedangkan independensi dalam penampilan merupakan persepsi pihak ke tiga bahwa seorang akuntan publik menjalankan proses audit dengan tidak berpihak pada salah satu kepentingan pihak manapun. Sedangkan independensi dalam penampilan akuntan publik hanya dapat ditentukan oleh persepsi masyarakat, khususnya pemakai laporan keuangan, terhadap sikap tidak memihak akuntan publik.

Persepsi mahasiswa terhadap pelaksanaan audit pada opini WTP Dalam kaitannya dengan indpendensi auditor merupakan sikap tidak memihak dalam melaksanakan audit pada Opini Wajar Tanpa Pengecualian (WTP), sebagaimana diatur dalam Standar Profesional Akuntan Publik (SPAP) yang ditetapkan oleh IAI.

Berdasarkan uraian tersebut maka dirumuskan hipotesis kedua :

H1: Terdapat perbedaan persepsi masalah Independensi auditor atas pelaksanaan audit pada opini WTP pada mahasiswa jurusan akuntansi dan manajemen.

\section{METODE PENELITIAN}

\subsection{Jenis dan sumber data}

Jenis penelitian yang akan dilakukan merupakan penelitian kauntitatif dengan uji perbedaan (uji komparasi) yaitu analisis statistik yang bertujuan untuk mengetahui perbedaan persepsi antara mahasiswa akuntansi dan manajemen terhadap pelaksanaan audit dan kualitas opini Wajar Tanpa Pengecualian (WTP) dalam kaitannya dengan tanggung jawab dan independensi auditor. Sumber data dalam penelitian ini adalah data primer yang secara langsung bersumber dari responden tanpa ada perantara, dalam hal ini adalah jawaban atas pertanyaan yang ada dalam kuesioner. 


\subsection{Sampel dan teknik pengambilan sampel}

Populasi dalam penelitian ini adalah mahasiswa Universitas Sam Ratulangi. Penelitian ini menggunakan purposive sampling, yang mana adalah teknik pengambilan sampel sumber data dengan pertimbangan tertentu (Sugiyono,2013:218-219). Dengan kata lain sampling dilakukan secara sengaja dimana peneliti menentukan sendiri sampel yang diambil karena ada kriteria tertentu yang sudah ditentukan.

Dalam penentuan sampel penelitian ini, peneliti memiliki beberapa kriteria yakni diantaranya:

1. Mahasiswa Fakultas Ekonomi dan Bisnis Universitas Sam Ratulangi

2. Mahasiswa akuntansi yang telah menempuh mata kuliah auditing dan paraktek audit.

3. Mahasiswa manajemen yang menempuh mata kuliah konsentrasi keuangan.

4. Sampel mewakili populasi yang ada.

Berdasarkan kriteria maka peneliti memilih 60 mahasiswa sebagai sampel dalam penelitian ini.

\subsection{Metode analisis}

Pemilihan metode penelitian dengan mempertimbangkan faktor jumlah variabel penelitian terdiri atas dua kelompok variabel pengujian yaitu mahasiswa akuntansi dan manajemen sehingga penelitian ini termasuk analisis data Independent Sample t-Test dengan bantuan program Statistical Product and Service Solution (SPSS). Analisis ini dimaksudkan untuk menguji perbandingan antar variabel dengan dua sampel bebas/independen.

\section{HASIL ANALISIS DAN PEMBAHASAN}

\subsection{Hasil analisis}

Dalam penelitian ini persentase jumlah distribusi kuesioner menurut jenis kelamin dapat dilihatpada Tabel 4.1.

Tabel 4.1 memperlihatkan distribusi kuesioner untuk jenis kelamin laki-laki sebanyak 28 orang atau 46, $7 \%$ dan untuk jenis kelamin perempuan sebanyak 32 orang atau 53,3\%.

Tabel 4.1 Persentase Jenis Kelamin

\begin{tabular}{|c|c|c|c|c|}
\hline & Frequency & Percent & $\begin{array}{c}\text { Valid } \\
\text { Percent }\end{array}$ & $\begin{array}{c}\text { Cumulative } \\
\text { Percent }\end{array}$ \\
\hline Valid laki-laki & 28 & 46,7 & 46,7 & 46,7 \\
\hline Perempuan & 32 & 53,3 & 53,3 & 100,0 \\
\hline Total & 60 & 100,0 & 100,0 & \\
\hline
\end{tabular}

Sumber :Hasil Pengolahan Data Primer dengan Alat Bantu SPSS Versi 23.0 
Hasil uji validitas data disajikan dalam Tabel 4.2 dan Tabel 4.3 berikut ini.

Tabel 4.2 Hasil Uji Validitas Tanggung Jawab Auditor

\begin{tabular}{cccc}
\hline Pertanyaan & $\begin{array}{c}\text { Nilai r } \\
\text { Hitung }\end{array}$ & $\begin{array}{c}\text { Sig(2- } \\
\text { Tailed })\end{array}$ & Status \\
\hline P1 &, $845^{* *}$ & 0,000 & Valid \\
P2 &, $668^{* *}$ & 0,000 & Valid \\
P3 &, $841^{* *}$ & 0,000 & Valid \\
P4 &, $643^{* *}$ & 0,000 & Valid \\
P5 &, $805^{* *}$ & 0,000 & Valid \\
P6 &, $795^{* *}$ & 0,000 & Valid \\
P7 &, $801^{* *}$ & 0,000 & Valid \\
P8 &, $780^{* *}$ & 0,000 & Valid \\
P9 &, $843^{* *}$ & 0,000 & Valid \\
P10 &, $787^{* *}$ & 0,000 & Valid \\
\hline$* *$ Correlation is significant at the 0.01 level (2-tailed).
\end{tabular}

Tabel 4.3 Hasil Uji Validitas Independensi Auditor

\begin{tabular}{cccc}
\hline Pertanyaan & $\begin{array}{c}\text { Nilai } \mathrm{r} \\
\text { Hitung }\end{array}$ & $\begin{array}{c}\text { Sig }(2- \\
\text { Tailed })\end{array}$ & Status \\
\hline Q1 &, $833^{* *}$ & 0,000 & Valid \\
Q2 &, $819^{* *}$ & 0,000 & Valid \\
Q3 &, $826^{* *}$ & 0,000 & Valid \\
Q4 &, $807^{* *}$ & 0,000 & Valid \\
Q5 &, $781^{* *}$ & 0,000 & Valid \\
Q6 &, $791^{* *}$ & 0,000 & Valid \\
Q7 &, $764^{* *}$ & 0,000 & Valid \\
Q8 &, $809^{* *}$ & 0,000 & Valid \\
Q9 &, $772^{* *}$ & 0,000 & Valid \\
** Correlation is significant at the 0.01 level (2-tailed).
\end{tabular}

Dari hasil uji validitas yang disajikan pada Tabel 4.2 dan 4.3 menunjukkan bahwa hampir semua item pernyataan berkorelasi positif dengan skor totalnya pada taraf signifikansi 0,01 yang ditunjukkan dengan tanda $* *$.

Hasil uji reliabilitas disajikan pada Tabel 4.4 berikut ini.

Tabel 4.4 Hasil Uji Reliabilitas

\begin{tabular}{|c|r|r|r|}
\hline \multicolumn{4}{|c|}{ Reliability Statistics } \\
\hline Variabel & $\begin{array}{c}\text { Cronbach's } \\
\text { Alpha }\end{array}$ & $\begin{array}{c}\text { N of } \\
\text { Items }\end{array}$ & Interpretasi \\
\hline $\begin{array}{c}\text { Tanggung Jawab } \\
\text { Auditor }\end{array}$ & 0,777 & 10 & Reliabel \\
\hline Independensi Auditor & 0,785 & 9 & Reliabel \\
\hline
\end{tabular}

Sumber :Hasil Pengolahan Data Primer dengan Alat Bantu SPSS Versi 23.0

Dari hasil analisis data seperti pada Tabel 4.4 diatas diperoleh koefisien Cronbach Alpha (a) sebesar 0,777untuk tanggung jawab auditor sehingga dapat dikatakan bahwa 
reliabilitasnya tinggi. Untuk independensi auditor nilai koefisien Alpha (a) sebesar 0,785, sehingga dapat dikatakan bahwa reliabilitasnya sangat tinggi.

Pada penelitian ini uji normalitas dilakukan dengan menggunakan teknik One Sample Kolmogorov Smirnov Test, yaitu pengujian dengan menggunakan dua sisi untuk membandingkan nilai taraf signifikansinya.

Analisis:

Ho : Data berdistribusi normal

$\mathrm{Ha} \quad$ : Data tidak berdistribusi normal

Hasil uji normalitas berdasarkan masing-masing kelompok mahasiswa akuntansi dan mahasiswa manajemen dan juga normalitas data secara keseluruhan disajikan pada Tabel 4.5 berikut ini.

Tabel 4.5 Hasil Uji Normalitas

One-Sample Kolmogorov-Smirnov Test

\begin{tabular}{|cc|r|r|}
\hline & & $\begin{array}{c}\text { Tanggung } \\
\text { Jawab } \\
\text { Auditor }\end{array}$ & $\begin{array}{c}\text { Independensi } \\
\text { Auditor }\end{array}$ \\
\hline Normal Parameters $^{a, b}$ & Mean & 60 & 60 \\
& Std. & 42,68 & 38,02 \\
Most Extreme & Absolute & 6,060 & 5,700 \\
Differences & Positive &, 114 &, 110 \\
& Negative &, 114 &, 110 \\
Test Statistic &,- 104 &,- 103 \\
Asymp. Sig. (2-tailed) &, 114 &, 110 \\
\hline
\end{tabular}

a. Test distribution is Normal.

b. Calculated from data.

c. Lilliefors Significance Correction.

Sumber :Hasil Pengolahan Data Primer dengan Alat Bantu SPSS Versi 23.0

Berdasarkan tabel di atas dapat dilihat bahwa Asymp.Sig.(2-tailed) untuk tanggung jawab sebesar 0,052 (> 0,05) sehingga datanya terdistribusi normal. Untuk independensi datanya terdistribusi normal karena nilai Asymp.Sig.(2-tailed) sebesar 0,067 (> 0,05). Sedangkan secara keseluruhan untuk tanggung jawab dan independensi auditor terdistribusi normal di mana nilai Asymp.Sig.(2-tailed) sebesar 0,119 (>0,05).

Hasil grup statistik untuk tanggung jawab dan independensi auditor (Tabel 4.2) sebagai berikut :

Tabel 4.6 Grup Statistik

Group Statistics

\begin{tabular}{|cc|c|c|c|c|}
\hline & Kelompok & $\mathrm{N}$ & Mean & $\begin{array}{c}\text { Std. } \\
\text { Deviation }\end{array}$ & $\begin{array}{c}\text { Std. Error } \\
\text { Mean }\end{array}$ \\
\hline Tanggung Jawab & Akuntansi & 30 & 47,30 & 3,064 &, 559 \\
Auditor & Manajemen & 30 & 38,07 & 4,608 &, 841 \\
\hline Independensi Auditor & Akuntansi & 30 & 42,43 & 2,873 &, 525 \\
& Manajemen & 30 & 33,60 & 4,182 &, 764 \\
\hline
\end{tabular}

Sumber :Hasil Pengolahan Data Primer dengan Alat Bantu SPSS Versi 23.0 
Tabel 4.7.

Hasil uji dengan menggunakan Uji Beda independen sample t-test di perlihatkan pada

Tabel 4.7 Hasil Uji Independent Sample T-Test

Independent Samples Test

\begin{tabular}{|c|c|c|c|c|c|c|c|c|c|c|}
\hline & \multicolumn{2}{|c|}{$\begin{array}{l}\text { Levene's Test for } \\
\text { Equality of Variances }\end{array}$} & \multicolumn{7}{|c|}{ t-test for Equality of Means } \\
\hline & & \multirow[b]{2}{*}{$\mathrm{F}$} & \multirow[b]{2}{*}{ Sig. } & \multirow[b]{2}{*}{$\mathrm{T}$} & \multirow[b]{2}{*}{$\mathrm{df}$} & \multirow{2}{*}{$\begin{array}{l}\text { Sig. (2- } \\
\text { tailed) }\end{array}$} & \multirow{2}{*}{$\begin{array}{c}\text { Mean } \\
\text { Difference }\end{array}$} & \multirow{2}{*}{$\begin{array}{l}\text { Std. Error } \\
\text { Difference }\end{array}$} & \multicolumn{2}{|c|}{$\begin{array}{l}95 \% \text { Confidence Interval } \\
\text { of the Difference }\end{array}$} \\
\hline & & & & & & & & & Lower & Upper \\
\hline \multirow[t]{2}{*}{$\begin{array}{l}\text { Tanggung Jawab } \\
\text { Auditor }\end{array}$} & $\begin{array}{l}\text { Equal variances } \\
\text { assumed }\end{array}$ & \multirow[t]{2}{*}{6,741} & \multirow[t]{2}{*}{, 012} & 9,138 & 58 & ,000 & 9,233 & 1,010 & 7,211 & 11,256 \\
\hline & $\begin{array}{l}\text { Equal variances } \\
\text { not assumed }\end{array}$ & & & 9,138 & 50,451 &, 000 & 9,233 & 1,010 & 7,204 & 11,262 \\
\hline \multirow[t]{2}{*}{$\begin{array}{l}\text { Independensi } \\
\text { Auditor }\end{array}$} & $\begin{array}{l}\text { Equal variances } \\
\text { assumed }\end{array}$ & \multirow[t]{2}{*}{7,336} & \multirow[t]{2}{*}{,009 } & 9,536 & 58 &, 000 & 8,833 & ,926 & 6,979 & 10,688 \\
\hline & $\begin{array}{l}\text { Equal variances } \\
\text { not assumed }\end{array}$ & & & 9,536 & 51,386 &, 000 & 8,833 & ,926 & 6,974 & 10,693 \\
\hline
\end{tabular}

Sumber :Hasil Pengolahan Data Primer dengan Alat Bantu SPSS Versi 23.0

Analisis:

Ho: Tidak terdapat perbedaan persepsi mahasiswa jurusan akuntansi dan manajemen.

Ha : Terdapat perbedaan persepsi mahasiswa jurusan akuntansi dan manajemen.

Kriteria pengujian (berdasarkan Probabilitas/ signifikansi) :

Ho diterima jika $\mathrm{P}$ value $>0,05$.

Ha diterima jika $\mathrm{P}$ value $<0,05$.

\subsection{Pembahasan}

Dalam penelitian ini independent sample t-test digunakan untuk mengetahui level signifikan perbedaan persepsi antara mahasiswa akuntansi dan manajemen Fakultas Ekonomi dan Bisnis Universitas Sam Ratulangi terhadap pelaksanaan audit pada opini WTP dalam kaitannya dengan tanggung jawab dan independensi auditor pada tingkat signifikan $\mathrm{P}=0,05$ Hipotesis nol (Ho) dan Hipotesis alternatif (Ha).

Hasil ini memperlihatkan dengan menggunakan 60 subjek sampel terdiri dari 30 mahasiswa jurusan akuntansi dan 30 mahasiswa jurusan manajemen, hasil penelitian ini menunjukkan bahwa nilai rata-rata (Mean) tanggung jawab auditor untuk mahasiswa jurusan akuntansi sebesar 47,30 sedangkan jurusan manajemen sebesar 38,07. Nilai rata-rata (Mean) Independensi auditor untuk mahasiswa jurusan akuntansi sebesar 42,43 sedangkan jurusan manajemen sebesar 33,60. Artinya nilai rata-rata (Mean) mahasiswa jurusan akuntansi dari tanggunggung jawab dan independensi auditor lebih tinggi dari nilai rata-rata (Mean) mahasiswa jurusan manajemen,sehingga mahasiswa akuntansi memiliki persepsi yang lebih baik dari mahasiswa jurusan manajemen. Lebih baiknya persepsi mahasiswa akuntansi karena mereka telah belajar mata kuliah audit, sementara mahasiswa manajemen tidak.

Pada hasil pengujian hipotesa berdasarkan penjelasan sebelumnya yaitu terlihat bahwa t-hitung untuk persepsi mahasiswa terhadap pelaksanaan audit pada opini WTP dalam kaitannya dengan tanggung jawab auditor sebesar 0,012 dan tingkat signifikan sebesar 0,000 atau $\mathrm{P}<0,05$, sehingga dalam hal ini Ho1 ditolak dan Ha1 diterima. Sehingga dapat disimpulkan bahwa persepsi siswa jurusan akuntansi dan mahasiswa jurusan manajemen berbeda secara signifikan, dan t-hitung untuk persepsi mahasiswa terhadap pelaksanaan audit pada opini WTP dalam kaitannya dengan Independensi auditor 0,09 dan tingkat signifikan sebesar 0,000 atau $\mathrm{P}<0,05$, sehingga dalam hal ini Ho2 ditolak dan Ha2 diterima. Sehingga dapat disimpulkan bahwa persepsi mahasiswa jurusan akuntansi dan mahasiswa jurusan manajemen berbeda secara signifikan. 


\section{KESIMPULAN DAN SARAN}

\subsection{Kesimpulan}

Dari hasil penelitian dengan judul “ Analisa Persepsi Mahasiswa Terhadap Pelaksanaan Audit Pada Opini WTP Dalam Kaitannya Dengan Tanggung Jawab dan Independensi Auditor", dapat ditarik kesimpulan.

Hasil penelitian yang menggunakan alat analisis Statistik Non Parametrik Independent Sampel T-Test yaitu, adanya expectation gap antara mahasiswa jurusan akuntansi dan mahasiswa jurusan manajemen atau terdapat perbedaan persepsi yang signifikan pada tiap responden antara, mahasiswa jurusan akuntansi dan mahasiswa jurusan manajemen terhadap tanggung jawab dan independensi auditor. Diperkuat dengan hasil uji, didapat hasil pengujian hipotesa terlihat bahwa t-hitung untuk persepsi mahasiswa terhadap pelaksanaan audit pada opini WTP dalam kaitannya dengan tanggung jawab auditor sebesar 0,012 dan tingkat signifikan sebesar 0,000 atau $\mathrm{P}<0,05$, sehingga dalam hal ini Ho1 ditolak dan Ha1 diterima. Sehingga dapat disimpulkan bahwa persepsi mahasiswa jurusan akuntansi dan mahasiswa jurusan manajemen berbeda secara signifikan, dan t-hitung untuk persepsi mahasiswa terhadap pelaksanaan audit pada opini WTP dalam kaitannya dengan Independensi auditor 0,09 dan tingkat signifikan sebesar 0,000 atau $\mathrm{P}<0,05$, sehingga dalam hal ini Ho2 ditolak dan Ha2 diterima. Sehingga dapat disimpulkan bahwa persepsi mahasiswa jurusan akuntansi dan mahasiswa jurusan manajemen berbeda secara signifikan karena mahasiswa jurusan akuntansi telah belajar mata kuliah audit, sementara mahasiswa manajemen tidak.

\subsection{Saran}

Saran-saran yang dapat diberikan berkaitan dengan hasil penelitian serta keterbatasan penelitian ini adalah sebagai berikut:

1. Penelitian selanjutnya diharapkan dapat menambah variabel dan obyek penelitian yang lebih luas lagi, bukan hanya mahasiswa saja.

2. Pengembangan kuesioner yang disesuaikan dengan kondisi dan penulisan kata yang mudah dipahami oleh responden untuk dapat digunakan dalam penelitian selanjutnya.

3. Penggunaan selain metode survey seperti metode interview dapat digunakan untuk mendapatkan komunikasi dua arah dengan subyek dan mendapatkan kejujuran jawaban subyek.

\section{DAFTAR PUSTAKA}

Agusti, R. \& Pertiwi, N. P. 2013. Pengaruh Kompetensi, Independensi dan Profesionalisme Terhadap Kualitas Audit. Jurnal Ekonomi. Vol. 21 No. 3

Arens, Alvin A. \& Loebbecke. 2012. Modern Auditing. Twelfth Edition. Pearson Education. Auliyana, Emy. 2017. Studi Kasus Fenomenologi Atas Opini Audit WTP di Kalangan Pejabat Pemenrintah Provinsi Jawa Timur. Jurnal Akuntansi Aktual. Vol. 4, No.1 Januari 2017.

Carmichael, Douglas. (1999). In Search of Concept of Independence. The CPA Journal. DeZoort \& Barney. 1991. A Public Accounting Career: The Gap Between Student Expectation and Accounting Staff Experiences. Accounting Horizons. P.7-12.

Dixon, R., Woodhead, A.D. \& Sohlima M. 2006. An investigation of the expectation gap in Egypt. Managerial Auditing Journal, 21 (3), 293-302.

Gamaliel, Hendrik 2007. Analisa Persepsi Mahasiswa Terhadap Hasil Audit dan Laporan Keuangan Auditan Dalam Kaitannya Dengan Tanggung Jawab, Keandalan dan Kegunaan Untuk Menilai Kinerja Perusahaan Masa Depan. Jurnal Organisasi dan Manajemen, 3 (2), 104-115. Manado: Universitas Sam Ratulangi. 
Gramling, Audrey \& Wallace. 1996. The Role of Undergraduated Auditing Coursework in Reducing the Expectation Gap. Issues in Accounting Education Vol.11. Spring 1996.

Guy, Dan \& Sullivan, Jerry, D. 1988. The Expectation Gap Standards. The Journal of Accountancy. April P 36-46.

Ikatan Akuntan Publik Indonesia. 2013. Standar Pemeriksaan Akuntan Publik. Salemba Empat. Jakarta.

Ikatan Akuntan Indonesia (IAI). Standar Akuntansi Keuangan (SAK) per efektif 1 Januari 2015. Salemba Empat. Jakarta.

Indrarto, Martin. 2005. Persepsi Pemakai Laporan Keuangan, Auditor, Akuntan Pendidik, dan Mahasiswa Akuntansi Terhadap Expectation gap Dalam Isu Proses Audit, Peran Auditor serta Kompetensi dan Independensi Auditor. Skripsi Universitas Sebelas Maret Surakarta.

Institut Akuntan Publik Indonesia. 2011. Standar Profesi Akuntan Publik (SPAP). Edisi Mei 2009. Penerbit ikatan Akuntan Publik Indonesia.Jakarta.

Koroy, Tri Ramaya. 2008. Pendeteksian Kecurangan (Fraud) Laporan Keuangan Oleh Auditor Eksternal. Jurnal Akuntansi keuangan, Vol. 10 No. 1.

Liggio, C (1974). The Expectation Gap: The Accountant's Legal Waterloo. Journal of Contemporary Business.

Mayangsari, Sekar. 2003. Pengaruh Keahlian Audit dan Independensi terhadap Pendapat Audit. Suatu Kuasi Eksperimen. Jurnal Riset akuntansi Indonesia, 6(1).

Nasser, Etty M. \& F. Agathasari Ayuningtyas. R. 2007. Expectation Gap Mahasiswa, Auditor dan Manajer terhadap Sikap dan Kinerja Auditor. Media Riset Akuntansi, Auditing dan Informasi. Vol.7. No.3. P.295-323. Fakultas Ekonomi Universitas Trisakti. Jakarta.

Rusliyawati \& Halim. 2008. Penginvestigasian Audit Expectation Gap pada Sektor Publik (Studi di Kalimantan Barat), Diponogoro. Journal of Accounting Vol.2, No 3.

Shaikh, J.M. \& Talha, M. 2003. Credibility and expectation gap in reporting on uncertainties. Managerial Auditing Journal, 18 (6), 517-529.

Sugiyono. 2013. Metode Penelitian Kuantitatif Kualitatif dan R\&D. Alfabeta. Bandung. 